\title{
Cesión y Nacionalidad en el Arbitraje de Inversión
}

\author{
Diego Brian Gosis ${ }^{1}$
}

\section{SUMARIO}

1. Introducción. 2. Cesiones anteriores a la existencia de una controversia. 3. Cesiones posteriores a la existencia de una controversia. 4. Cesiones posteriores al dictado del Laudo. 4.1. Efectos relativos a los recursos. 4.2. Efectos relativos a la protección diplomática. 4.3. Efectos relativos al reconocimiento y ejecución del laudo. 5. Conclusión

\section{INTRODUCCIÓN}

"There was also international
public arbitration, which was
somehow a different beast"

Loukns Mistelis?

Comenzada la segunda década del siglo XXI parece evidente que el derecho internacional de las inversiones $y$, especial-

1. El autor es socio del bufete Remaggi, Pico, Jessen \& Asociados, de Buenos Aires, Argentina, y of Counsel de la Procuración del Tesoro de la Nación Argentina en materia de arbitraje internacional comercial y de inversión. Puede ser contactado a través de su dirección de correo electrónico dgosis a rpjabogados com.

2. Mistrilis, Loukas, del prólogo a McLacilan, Campbell, Suore, Laurence y Weinicir, Matthew: Intemational Investment Arbitration-Substantive Principles (Oxford University Press, 2007), p. vii. 
mente, su arista más visible -la resolución mediante arbitraje de las disputas entre inversores y Estados- constituyen, en toda regla, una rama separada del derecho. A pesar de que los frutos que penden de esta rama se nutren de instrumentos jurídicos de diversa fuente -acuerdos con particulares, leyes nacionales de inversión, tratados bilaterales y multilaterales, y reglas consuetudinarias de variados alcances geográficos-, todos ellos refieren a supuestos de responsabilidad de los Estados por el trato dispensado en su territorio a extranjeros en violación a sus obligaciones relativas a inversiones. ${ }^{3}$

Las dificultades para establecer de manera acabada las múltiples fuentes y contenidos específicos de las obligaciones de derecho internacional de los Estados han llevado a la Comisión de Derecho Internacional de las Naciones Unidas (la "CDI") a sistematizar los principios relativos a la responsabilidad de los Estados con prescindencia del análisis de esos elementos en su Proyecto de Artículos sobre Responsabilidad de los Estados por Hechos Internacionalmente Ilícitos. ${ }^{\top}$ Comentando el alcance de ese Proyecto, la CDI expresaba que

los presentes artículos tratan de toda la esfera de la responsabilidad de los Estados. En consecuencia, no se limitan a la violación de obligaciones de carácter bilateral, por ejemplo en virtud de un tratado bilateral con otro Estado. Los artículos se aplican a todas las obligaciones internacionales de los Estados, ya se trate de obligaciones para con uno o varios Estados, para con un particular o un grupo, o para con la comunidad internacional en conjunto. ${ }^{5}$

3. No nos detendremos en estas páginas más que lo imprescindible en las abundantes disquisiciones -todas ellas de gran interés y relevancia general- relativas a ia calificación de "extranjero" e "inversión" a efectos de esta definición y que han resultado, ellas mismas, fértiles valles para el debate en esta area del derecho. Para un detallado indice de los diversos maicriales existentes en este punto, recomendamos la lectura del comentario al articulo 25 del Convenio CIADI en la obra de SCHREUER, Cristoph, The ICSID Convention: A Commentary (Cambridge University Press, 2009), pp. 71 a 347.

4. Adoptado por ła Comisión de Derecho Internacional en su 53ra. Sesión, en 2001, y disponible en idioma inglés, conjuntamente con los comentarios de esa comisión, en http://untreaty.un.org/ilc/texts/instruments/english/commentaries/9_6_2001.pdf.

5. Proyecto de Articulos sobre Responsabilidad de los Estados por Hechos Internacionalmente llicitos, Comentario General, \$\$(5). 
De manera análoga, en las páginas que siguen nos referiremos al efecto que la cesión de ciertos derechos o reclamos a cesionarios de nacionalidades diversas puede tener sobre los dispositivos procesales aplicables a los reclamos relativos a esa responsabilidad, sin abocarnos a analizar el origen o alcances de ésta.

Esas cesiones pueden afectar a los derechos o reclamos de un inversor en diversas etapas de la existencia de la inversión que constituye el objeto del reclamo. Como en el enigma de la esfinge de Tebas, ${ }^{6}$ encontraremos que los elementos en que se apoya la existencia de una inversión o reclamo tutelados bajo el derecho internacional de las inversiones varían en cada una de las tres etapas que analizaremos separadamente: (i) cuando existe la inversión sin que haya surgido aún un reclamo, (ii) cuando existe ya el reclamo y, finalmente, (iii) cuando existe ya el laudo. Por los motivos que esbozamos a continuación, una transferencia que ocurra en cada uno de esos momentos tendrá efectos distintos sobre los derechos que se pretenden transferir, lo que podría llevar, incluso, a hacer inviable un reclamo arbitral o la ejecución del laudo que se haya emitido.

6. Cuenta el mito que, a las pucrtas de la Tebas griega, una esfinge formulaba a los viajeros un cnigma y castigaba con la mucrte a quienes no podian resolverlo. Según el mito, cuando Edipo consiguió darle la respuesta correcta - tras haberla recibido en sueños-. ta esfinge, presa de una furia incontenible, se dio mucrte. Aristófanes de Bizancio, en su glosa al Edipo Ray' de Sófocles, refiere que el enigma rezaba: "Existe sobre la tierra un ser bipedo y cuadrupedo, que tiene sólo una voz, y es tarnbién tripode. Es el único que cambia su aspecto de cuantos seres se mueven por tierra, aire o mar. Pero, cuando anda apoyado en más pies, entonces la movilidad de sus miembros es mucho más débil". La respuesta de Edipo, según la misma fuente, habria sido "Escucha, aun cuando no quieras, Musa de mal agüero de los muertos, mi voz, que es el fin de tu locura. Te has referido al hombre, que cuando se arrastra por tierra, al principio, nace del vientre de la madre como indefenso cuadrípedo y, al ser viejo, ą̧oya su bastón como un iereer pie, cargando el cuello doblado por la vejez".

7. A pesar de que las analogias con la gesta edipica podrian utilizarse para referimos a una notable variedad de debates de gran vigencia en el marco del arbitraje de inversión, lamentamos informar al lector que no nos pronunciaremos en estas lineas sobre cuestiones de endogamia entre los circulos practicantes del arbitraje, ni sobre los efectos de las vinculaciones no reveladas en la génesis de ciertas decisiones arbitrales, ni -finalmente- sobre el efecto de las normas de ius cogens sobre el alcance de los acuerdos y tratados positivos de inversión. 


\section{Cesiones anteriores a la existencia DE UNA CONTROVERSIA}

Para comenzar, debe distinguirse la situación en la que, a lo largo de la vida de un cierto proyecto productivo, el inversor extranjero que es su titular o controlante decide transferirlo -ya sea a través de la venta de las acciones de la sociedad que lo explote, o de la transferencia a título individual o colectivo de activos vinculados a ese proyecto- con el propósito principal de despertar eventualmente la jurisdicción de un tribunal de arbitraje de inversión, de aquella otra en la que la operación tiene motivaciones puramente comerciales o, incluso, societarias o impositivas. $^{8}$

Respecto del primer caso, mencionaremos, como cuestión liminar, que los tribunales han demostrado una limitada receptividad a reconocer la validez a efectos jurisdiccionales de tales acuerdos de transferencia. ${ }^{9}$ Ello es congruente con el venerable principio de que nadie puede transferir derechos mayores o mejores que los que posee, $10 \mathrm{y}$ con el respeto al objeto y propósito que los Estados tuvieron en cuenta al diseñar y obligarse bajo el régimen de arbitraje de inversión," que consiste en lo que algunos autores han denominado el quid pro quo del derecho internacional de las inversiones, en virtud del cual los Estados se

3. Ver, por ejempio. Tokios Fokeles c. Ucrania, Caso CIADI Nro. ARB/02/18, Laudo del 26 de juito de 2007 , $\$ 111$, en donde se discuten los efectos de ciertas operaciones ocurridas dentro del grupo de empresas respectivo sobre la jurisdicción de los tribunales arbitrales.

9. Ver, por ejemplo, Schreuer, op. cit., comentario al articulo 25 del Convenio ClADl, $\$ 350$ (“...the readiness of tribumals to accę̧t arrangements designed to attract ICSID's jurisdiction is not unlimited").

10. Ver, por cjemplo, Mihaly c. Sri Lanka, Caso CIADI Nro. ARB 00/2, Laudo del 15 de marzo de 2002 , ข24 ("...nemo dat quod non haher or nemo potiarem potest transfere quam ipse habet"). Llana la atención, en este sentido, la decisión adoptada en dacoven c. Venezuela, donde el tribunal se consideró competente al entender que, a pesar de que el inversor originario no era nacional de un Estado contratante del ClADI, las partes del contrato pertinente habian pactado la jurisdicción de ese Centro para el caso de que se transfirieran las acciones de la sociedad operativa a un nacional de un Estado contratante del CIADI, lo que el Tribunal entendió que en definitiva habia sucedido (Alutopista Concesionada de Venezuela c. Venezuela. Caso ClADI Nro. ARB/00/5, Decisión de Jurisdicción del 27 de septiembre de 2001, §124 ("Aucoven c. Venezucla, Decisión de Jurisdicción")).

11. Ver, por ejemplo, Phoenix detion c. República Checa, Caso ClADI Nro. ARB/06/5, Laudo del IS de abril de 2009, $\$ 144$ ("Phoenix c. Republica Checa") ("It is indecd the Tribumal ss view that to accept jurisdiction in this case would go against the hasic objectives anderlying the ICSID Convention as ucll as these of bilateral investment treatics"). 
han comprometido a otorgar un cierto número y calidad de protecciones a cambio de recibir inversiones de los nacionales de los restantes Estados miembros del sistema de derecho internacional de las inversiones. ${ }^{12}$

Respecto del segundo caso, la disponibilidad para el cesionario de los mecanismos sustantivos o procesales de protección de la inversión dependerá, principalmente, de si el cesionario califica como inversor protegido bajo los instrumentos respectivos, de si la adquisición o la operación ulterior del proyecto por el cesionario representa, para este último y con independencia de los actos anteriores del cedente, un emprendimiento que pueda calificar como una 'inversión' a efectos de esa protección y de si puede, en las circunstancias del caso, considerarse que las medidas que se impugnan como violatorias de las obligaciones internacionales del Estado afectaron a la inversión realizada por el cesionario.

La cuestión ha sido recientemente analizada por el tribunal de Phoenix Action c. República Checa, que llegó a la siguiente conclusión:

El Demandante presentó la notificación por parte de Phoenix de una disputa relacionada con una inversión a la República Checa el 2 de marzo de 2003, aún antes de la inscripción de su titularidad de las dos empresas checas ante la República Checa, y solamente dos meses después de su adquisición de las Empresas Benet, y presentó su reclamo ante el Centro once meses después. En su carta al Ministro de Finanzas de la República Checa, Phoenix sostenía que una serie de hechos habían constituido violaciones al TBI. Si uno mirara solamente a los eventos ocurridos luego de la inversión, que es lo que debe hacerse para respetar los principios de aplicación ratione temporis del TBI entre Israel y la República Checa, la conclusión inevitable es que el

12. Douglas, Zachary, The International Law of Investment Clams (Cambridge University Press, 2009). p. 136 ("Hence, the protection is only operative once the forcign national has satisficd its part of the quid pro quo by making an insestment in the host state"). 
Demandante, cuando elevó por primera vez su reclamo ante el CIADI, pretendía sostener que una demora de dos meses en resolver los problemas que afectaban a su inversión representaban una violación de los estándares de trato justo y equitativo y de protección y seguridad plenas(...). La mera enunciación de tal pretensión muestra a las claras que lo que verdaderamente estaba en discusión eran violaciones y daños previos a la inversión. ${ }^{13}$

El tribunal de Phoenix Action llegó, por este y otros motivos, a la conclusión de que no tenía jurisdicción para resolver la controversia, lo que nos lleva a considerar que, en casos de cesión, a efectos de determinar la existencia de una inversión protegida que pueda, por ulteriores violaciones a obligaciones internacionales por parte del Estado en cuyo territorio la inversión ha sido realizada, dar lugar a un reclamo arbitrable, deberemos centrar nuestra atención en la situación del cesionario y no en la del cedente.

Para demostrar esta hipótesis ${ }^{14}$ imaginemos una inversión realizada originalmente por un nacional de un Estado contratante del Convenio sobre Arreglo de Diferencias Relativas a Inversiones entre Estados y Nacionales de Otros Estados (el "Convenio CIADI" o el "Convenio") en el territorio de otro Estado contratante, e imaginemos también que existe entre ambos Estados un tratado bilateral de inversiones ("TBI") que permite al inversor acceder a un arbitraje CIADI en caso de controversias relacionadas con la inversión. Si la inversión fuera cedida antes de que se origine una controversia a un inversor nacional del Estado receptor, o de un Estado que no fuera parte del Convenio CIADI, el resultado sería, casi sin dudarlo, que

13. Phoenix c. Repuiblica Checa, \$\$ 138 (traducción librc).

14. Centraremos nuestro analisis, a efectos de este ejemplo, en la posibilidad de arbitrar las controversias bajo el sistema de arbitraje del ClADI, por verse alli reflejadas de manera más sistemática los problcmas de nacionalidad que discutiremos a lo largo de estas lineas, aunque consideramos que, mutatis mutandis, cuanto aqui se dice puede aplicarse sin mayores diferencias conceptuales a la cesibilidad de las restantes protecciones contenidas en el régimen del derecho internacional de las inversiones. Piénsese, por cjemplo, en la transferibilidad de las protecciones sustantivas otorgadas bajo un tratado bilateral en particular a ulteriores inversores de otras nacionalidades. 
cualquier acceso a un arbitraje CIADI quedaría vedado para el adquirente. ${ }^{15}$ Si modificáramos, ceteris paribus, la nacionalidad del cesionario, tal que éste fuera nacional de cualquier Estado parte del Convenio CIADI distinto del Estado receptor, encontraríamos, casi sin dudarlo también, que éste tendría acceso a la jurisdicción de un tribunal CIADI.

$\mathrm{Si}$, por el contrario, un nacional de un Estado que no es parte del Convenio CIADI cediera un activo localizado en territorio de un Estado parte de ese Convenio -y que pudiera de otro modo calificar como inversión bajo ese instrumento- a un connacional o a un inversor de otro Estado que tampoco fuera parte del Convenio CIADI, consideramos que ninguna violación al derecho internacional en que pudiera incurrir el Estado receptor podrá despertar la jurisdicción de un tribunal del CIADI. ${ }^{16} \mathrm{Si}$, como antes hiciéramos, modificáramos, ceteris paribus, la nacionalidad del cesionario, tal que éste fuera nacional de un Estado parte del Convenio CIADI distinto del Estado receptor, consideramos que ese inversor tendrá acceso al sistema de arbitraje del Convenio CIADI, salvo en la medida en que, como mencionábamos, el propósito de la operación fuera, justamente, el de generar esa posibilidad jurisdiccional.

Como se ve, en cualquiera de las posibilidades matemáticas de combinación, si el cesionario tiene, por su propia situación y actividad respecto de la inversión, derecho a invocar las disposi-

15. Cuando el inversor fuera nacional de otro Estado que no fuera un Estado contratante del Convenio CIADI, sin embargo, se mantendria la posibilidad de constituir un tribunal bajo las reglas del Mecanismo Complementario del CIADI. Conforme el articulo 2(a) del Reglamento del Mecanismo Complementario del CIADI, ese Centro podrá administrar procedimientos bajo tal reglamento cuando el Estado parte en la controversia o el Estado del cual el inversor que sea parte en la controversia sea nacional no sean Estados contratanies bajo el Convenio CIADI. El articulo 3 del Reglamento del Mecanismo Complementario agrega el requisito de que, para que el Secretario General del CIADI pucda aceptar una solicitud de administrar un procedimiento bajo ese reglamento en tal circunstancia, las partes acuerden que, "en el caso de que al tiempo de la iniciación del procedimiento se hubieren cumplido los requisitos jurisdiccionales ratione personac" del Convenio CIADI, el procedimiento tramite bajo el Convenio CLADI y no bajo cl Mecanismo Complementario. Nólese que esta posibilidad no estaria disponible cuando el inversor fuera de la nacionalidad del Estado parte en la controversia (Reglamento del Mecanismo Complementario, §2).

16. Ver la nota al pie anterior respecto de ta posibilidad de excitar la jurisdicción de tribunales arbitrales bajo otros sistemas de resoluciön de controversias, como el Mecanismo Complementario del CIADI. 
ciones del Convenio CIADI, la carencia de esa posibilidad para el cedente -a salvo el requisito de que la operación no haya sido celebrada in fraudem legis con el solo o principal propósito de generar jurisdicción- no afectará negativamente las alternativas jurisdiccionales al alcance del cesionario. $\mathrm{Si}$, por el contrario, el cesionario no tiene, por su situación o actividad respecto de la inversión, acceso a la jurisdicción de un tribunal del CIADI, el hecho de que el cedente lo hubiera tenido antes de la cesión en nada mejora su situación, y le estará vedado al adquirente arbitrar en ese foro los reclamos que puedan surgir.

\section{Cesiones posteriores a la existencia DE UNA CONTROVERSIA}

Una vez que llegamos a la conclusión de que una cesión celebrada con el sólo o principal objeto de atraer la jurisdicción de un tribunal de arbitraje de inversión tiene un destino sesgado al fracaso, ${ }^{17}$ comenzaremos esta sección agregando que este destino se torna todavía más ominoso si esa cesión se realiza cuando la controversia ya existe, ${ }^{18}$ ya que, como comenta el Prof. SCHREUER, "no serán aceptadas cesiones oportunistas discñadas para transformar disputas ya existentes en cuestiones sometidas a la jurisdicción del CIADI".19

Así introducidos en la cuestión, pasaremos a analizar los elementos relevantes para determinar los efectos que la cesión de un reclamo -o del activo al que se refiere-a un tercero tendrá en la viabilidad de un reclamo arbitral. Para hacerlo volveremos a centrarnos primariamente $-\mathrm{y}$ por idénticos motivos-, en la jurisdicción y práctica de los tribunales del CIADI. ${ }^{20}$

17. Ver la nota al pic \#9 supra.

18. Ver SCIiReuer, op. cit, comentario al articulo 25 del Convenio CIADI, $\$ 350$ ("In particular, tribunals have looked with disfavour upon sinuations in which the investur sought to transfer an existing claim from a claimant").

19. $H, \$ 360$

20. Ver la nota al pic \#14 supra. 
Bajo el sistema del Convenio CIADI, la jurisdicción del Centro dependerá de las nacionalidades de las partes demandantes y demandadas ${ }^{21}$ al momento de consentir en someter la controversia a arbitraje y al momento de registrarse la solicitud de arbitraje -en el caso de inversores personas físicas- o al momento de consentirse la jurisdicción del CIADI -en el caso de inversores personas jurídicas-,, 2 que constituyen las fechas críticas para llegar a esa determinación. En el marco de las controversias derivadas de tratados bilaterales o multilaterales de inversión, esto sucede casi exclusivamente después de trabada la controversia, y el consentimiento del inversor se expresa frecuentemente en el acto mismo de la notificación del reclamo al Estado receptor o, cuando el tratado correspondiente no requiere el agotamiento de consultas o negociaciones previas, junto con la misma solicitud de arbitraje. ${ }^{23}$

Si bien muchos sostienen, siguiendo la posición adoptada por la Corte Internacional de Justicia respecto de su propia jurisdicción, ${ }^{24}$ que, luego del momento en el que se fija la jurisdicción

21. A pesar de que, estadisticamente, resulta habitual encontrar uno o más inversores de una única nacionalidad entre los demandantes, y un único Estado entre los demandados, no existen motivos juridicos por los que -cumplidos ciertos requisitos que exeeden el marco de este estudio- la situación no pueda ser la inversa o, incluso, para que dos o más Estados aparezcan como demandados o demandantes en un misma procedimiento. Esto podría fäcilmente suceder en el marco de acuerdas multinacionales de inversión, a como consccuencia de tratados multilaterales o proyectos transnacionales. A modo de ejemplo, el autor ba participado en procesos ante tribunales del CIADI en los que se formulaban reclamos bajo dos y hasta tres tratados bilaterales de manera simultanea, dada la diferente nacionalidad de las partes demandantes.

22. Arg. Convenio CIADI, \$25(2). A criterio del tribunal de Vacumm Salt c. Gluana, el fundamento de esta diferente aproximación en cl caso de personas fisicas y juridicas podrja encontrarse en que las personas fisicas son menos proclives a sufrir una pérdida de su nacionalidad de manera involuntaria que las personas juridicas - lo que podria suceder, por ejemplo, en caso de una expropiación de las acciones de la persona juridica-, lo que justifica que se requiera en las primeras una constatación de la nacionalidad en esas dos instancias separadas ('/acuum Salt c. Ghana, Caso CIADI No. ARB/92/1. Laudo del 16 de febrero de 1994, nota al pie \$9 ("Vacuum Salt c. Glana")). Para un indice de las diversas cuestiones a que esta diversa determinación puede dar lugar ver SCHREUER, op cit , comentario al articulo $25 \mathrm{del}$ Convenio ClADI, $\$ 35$.

23. Si bien la situación es otra en caso de que el consentimiento haya sido prestado en un acuerdo de inversion, y algunas de las decisiones que se comentan a lo largo de estas paginas se refieren a esos supuestos, supondremos a efectos de este ensayo -arbitrariamente y por una cuestión de orden expositivo- que el surgimiento de la controversia precede a las fechas criticas establecidas por referencia al articulo 25(2) del Convenio CIADI, lo que acontece en una extensa mayoria de los casos con decisiones reportadas durante la última década.

24. Ver, por ejemplo. Caso Relativo a la Orfen de drresto del 11 de abril de 2000 (Congo c. Bélgica). C.I.J., Sentencia del 14 de febrero de 2002, I C.J Reports 2002, , p. I, \$26 ("...if the Comer has juris- 
de un tribunal de inversión -esto es, luego de esas 'fechas críticas'- ningún hecho ulterior puede afectarla, 25 entendemos que ese apotegma no resulta necesariamente de aplicación en el contexto especial del Convenio CIADI.

En efecto, la jurisdicción de tribunales bajo el Convenio CIADI surge como consecuencia del acuerdo allí expresado entre los Estados contratantes, y sería ilógico y carente de todo sentido y axiología permitir que se ejerza esa jurisdicción si ello lleva a un resultado "manifiestamente absurdo o irrazonable". 26 A modo de ejemplo, el tribunal de Vivendi II ha considerado que ese principio caería en caso de que, con posterioridad a las fechas críticas, un comité ad hoc del CIADI anulara la decisión que asume jurisdicción, ${ }^{27}$ al tiempo que el tribunal de Vacuum Salt c. Glana consideró que la iniciación de un arbitraje CIADI por parte de una sociedad del Estado demandado que hubiera dejado de ser controlada por nacionales de otro Estado contratante del Convenio CIADI luego de la fecha crítica establecida en el artículo 25(2) de ese instrumento violaría las reglas de interpretación derivadas de la Convención de Viena sobre Derecho de los Tratados.28 29

diction on the date the case is referred to it, it contimues to do so regariless of subsequent events"). Fer también la decisión de la Corte Intemacional de Justicia en el Case Relativo a Cuestiones de Interpretación y Aplicacion de la Convención de Montreal de 1971 Surgidas del Incidente déren de Lockerbic (Libia c. Estados Unidos), Decisión sobre Objeciones Preliminares del $27 \mathrm{de}$ febrero de 1998, I.C.J. Reports 1998, p. 115, \$37, y las decisiones alli citadas.

25. Ver, por cjemplo, Compañia de Aguas del Aconquija S. A. y Vivendi Universal c. República Argentina, Caso CIADI No. ARB/97/3 ("Vivendi (II) c. Argentina"), Decisión de Jurisdieción del 14 de noviembre de $2005, \$ 63$ ("... una vez que ha sido establecida, la juriscticción del tribunal no puede ser derogada"). Ver también Goetz y otms c. Burutid. Caso CIADI No. ARB/95/3, Laudo de! 10 de febrero de 1999. \$72; Zhimvali Development Lıd. c. Repuihlica de Gcorgia. Caso CIADI No. ARB/00/1. Laudo del 24 de encro de 2003, \$24, y, en general, SCHREuER, up. cit., comentario al articulo $25 \mathrm{del}$ Convenio CIADI, $\S 36$.

26. Convención de Viena sobre Derecho de los Tratados, \$32(b). Si bien el Convenio de Washington de 1965 entro en vigor con anterioridad a la Convención de Viena de 1969, es pacifica la interpretación de que sus disposiciones sobre regias de interpretación (contenidas en los $\$ \S 31$ a 35 de la Convención de Viena) resultan aplicables cn cuanto codifican "reglas y principios de interpretación de tratados generalmente aceptados en el derecho internacional" (Amco Asia Corporation y otrus c. Repuiblica de Indenesia, Caso CIADI No. ARB/81/1. Decisión de Anulación del 16 de mayo de 1986, $\$ \$ 18-21$, citado por Scheurk. op. cit., traducción libre). Jer kambién el caso bajo el TLCAN Mondel International Lul. c. Estados Unidos de America, Caso CIADI No. ARB(AF) 99/2, Laudo bajo las Reglas del Mecanismo Complementario del CIADI del 11 de octubre de 2002, $\$ 42$.

27. Jivendi II c. Argentina, Decision de Jurisdicción. $\$ 63$. 
Sin llegar a pronunciarse en términos tan concluyentes, diversos tribunales han prestado igualmente atención a la nacionalidad del inversor luego de prestado el consentimiento para determinar su competencia ratione personae, , $^{30}$ lo que demuestra que el análisis no acababa -a su entender- en la fecha crítica establecida en el artículo 25(2) del Convenio CIADI. Comentando sobre estas decisiones, se ha dicho que

"las declaraciones [de otros tribunales] respecto de que el único momento relevante es la fecha del consentimiento han sido puestos en duda por preocupaciones relativas a desarrollos ulteriores, y por cierta intranquilidad respecto de la posibilidad de que se abra la jurisdicción del CIADI a personas jurídicas que, luego de esa fecha, hayan pasado a ser controladas por nacionales del Estado receptor". ${ }^{31}$

Antes de abandonar la cuestión de las fechas en las que se consolida la jurisdicción del CIADI, nos detendremos por un instante en la llamativa solución adoptada por el tribunal de Aucoven c. Venezuela en este punto. ${ }^{32}$ Ese tribunal consideró que, en sentido inverso a la lectura habitual de la cuestión de las fechas críticas en la jurisprudencia del CIADI, a pesar de que al momento de otorgarse el instrumento que contenía el consentimiento a arbitrar, el inversor era de nacionalidad mexicana -es decir, de un Estado no contratante del Convenio CIADI-, y de que el demandante sólo calificó como "nacional de otro Estado

28. Jacurm Salt c. Ghana, nota al pie $\$ 6$ del Laudo.

29. Como nota de color, en el caso Locwen c. Estados Unidos, un tribunal constituido bajo el Mecarismo Complementario del CIADI resolviá que el TLCAN entre Estados Unidos, México y Canadá preveia, a diferencia del articulo $25 \mathrm{del}$ Convenio CIADI, un requisito de que se mantuviera de manera constante la nacionalidad del inversor hasta la fecha en que se resolviera la controversia, y procedió a declarar que habia perdido su jurisdicción aún luego de celebrada la audiencia de mérito (Loeren c. Estados Unidos, Caso CIADI No. ARB(AF)/98/3, Laudo del 26 de junio de 2003, §1).

30. Ver, por ejemplo, Sociuté Onest Africaine des Bétons Industriels c. Senegal, Caso CIADI No. ARB/82/l, Decisión de Jurisdicción del 1 de agosto de 1984, \$4!, Liberian Eastern Timber Corporation c. República de Liberia, Caso CIADI No, ARB/83/2, Decisión de Jurisdicción de! 24 de octubre de 1984, 2 ICSID Reports 349, 351, Amco Asia Corporation y otros c. República de Indonesia, Caso ClADI No. ARB/8I/1. Decisión de Juristicción del 25 de scptiembre de 1983 , $\$ 14$ (ii).

3I. SCIREUER, op. cit., comentario al artículo 25 del Convenio CIADI, $\$ 883$ (traducción libre).

32. Ver nuestro comentario anterior en la nota al pic \#10 supra. 
contratante" a efectos del artículo 25(2)(b) del Convenio CIADI luego de esa fecha crítica, el inversor podía adquirir en ese momento posterior la posibilidad de invocar válidamente la jurisdicción del Centro. ${ }^{33}$

Finalmente, nos dedicaremos brevemente a un supuesto particular, que es el de las cesiones derivadas de cobros percibidos por el inversor originario como consecuencia de coberturas de seguros de riesgo político. Si bien coincidimos, como cuestión general, con la apropiada afirmación del Prof. SCHREUer acerca de que "no puede asumirse con ligereza...que el consentimiento pueda ser transferido a otras partes sin la aprobación de la contraparte al acuerto originario de donde surge el consentimiento", ${ }^{34}$ consideramos que, una vez que un asegurador ha desinteresado al inversor damnificado por una violación de derecho internacional, y sujeto a que los requisitos ratione personae respecto de la nacionalidad del asegurador se cumplan en la especie, ${ }^{35}$ no parecería haber obstáculos sustanciales para que el asegurador/pagador reclame por esas violaciones, subrogándose en los derechos del inversor originario.

De hecho, los tratados bilaterales acostumbran contener formulaciones que constituyen esa 'aprobación', cuando prevén que los organismos aseguradores del Estado del que el inversor es nacional puedan subrogarse en todos sus derechos y reclamos en la medida de la indemnización pagada al inversor, aunque

33. En la adopciòn de csa tesitura, el tribunal asignó gran importancia a que, en su interpretación, las partes habian pactado especificamente esa posibilidad en el contrato del que surgia la jurisdicción del centro (Aucosen c. Venezuela, Decisjón de Jurisdicción, \$124), lo que aviva la discusión acerca de si las partes podrian haber pactado una exiensión de la jurisdicción del CIADI distinta y más amplia que la cstablecida en el propio Convenio CIADI.

34. SCHREUER, op. cit., comentario al articulo 25 del Convenio CIADI, $\$ 303$ (traducción libre).

35. Scirreuer sostiene, de manera casi enfätica, que el dispositivo CIADI no cstaria disponible cuando los aseguradores fucran Estados, entidades estatales u organismos multilaterales ("The clear wording of Art. 25(I) cannot he re-interpreted to cover disputtes involving States, State agencies or international organizations on the investor $\xi$ side", ld., $\$ 365$ ), aunque la decision adoptada en CSOB c. Eslovagnia parece contradecir este argumento (Ceskoslovenska Obchodni Banka c. Eslovaquia. Caso CIADI Nro. ARB/97/4, Decisión de Jurisdicción del 24 de mayo de 1999, \$332) ("...the transfer of the econonic risk in the outcome of a dispute should not and has not been deemed to affect the standing of a claimant in an ICSID prrcecding, negardless whether or not the beneficial owner is a State Parț or a private party"). 
debemos anotar también la existencia de tratados bilaterales en los que esa subrogación en los derechos excluye específicamente la posibilidad de interponer un reclamo bajo los mecanismos de resolución de controversias permitidos al inversor bajo el $\mathrm{TBI},{ }^{36}$ en cuyo caso, por supuesto, no existirá jurisdicción bajo el Convenio CIADI.

Cuanto antecede se refiere a la cuestión de los efectos jurisdiccionales de las transferencias de reclamos o inversiones ocurridas luego del surgimiento de una controversia. De manera adicional a ello, debemos dedicarnos, aunque más no sea tangencialmente, a un aspecto no menos interesante, como es el de los efectos de esas transferencias, o de la práctica que de ellas se hace, respecto de la viabilidad del mérito de un reclamo.

Por motivos que no encuentran hoy lugar entre estas páginas, ${ }^{37}$ puede identificarse en el arbitraje de inversión una tendencia creciente a reclamar en concepto de daños sumas exorbitantes, que exceden muchas veces en múltiplos notables las sumas invertidas o las expectativas de ingresos derivados de la inversión. ${ }^{38}$ Dado que el valor de mercado de la inversión, con razón o sin ella, resulta finalmente el indicador más utilizado para la cuantificación de los daños, ${ }^{39}$ cualquier cesión -total o parcial-

36. Ver, por cjempla, el TBl Argentina-México, \$\$6 ("En caso de que una Parle Contratante o entidad por clla designada haya olorgado cualquier garantia financicra sobre riesgos no comerciales en relación con una inversión efectuada por sus inversores en el territorio de la otra Parte Contratante y desde el momento $\mathrm{cn}$ que la primera Parte Contratante o su entidad designada haya realizado pago alguno con cargo a la garantía concedida, la primera Parte Contratante o la entidad designada será beneficiaria directa de todo tipo de pagos a que pudiese ser acreedor el inversor. En caso de controversia, única. mente el inverser nodrá iniciar o narticipar en nrocedimicntos ante los tribunales nacionales o some: terla a tribunales de arbitraje internacional de acuerdo con las disposiciones del Artículo Décimo y del Anexo del presente Acuerdo") (el subrayado nos pertenece).

37. Para una inteligente descripeión del fenómeno, ver ReED, Lucy, Less is More, More or Less, en Norld Arhitration and Mediation Review; Vol. 2:4 (2008), pp. 101 y ss.

38. Tómesc, a guisa de cjemplo, el caso de Saba Fakes $c$. Tiarquia, en el que el demandante reclamaba una suma cercana a los USD 19.000 .000 .000 por la presunta expropiación de acciones que habia adquirido por USD 3.800 algunos dias antes (Sahra Fakes c. Turquia, Caso CIADI Nro. ARB/07/20, Laudo del 14 đe julio de 2010, \$ุ139).

39. Como sostienen Wissiurg y RYAN, “...demandantes, demandados y tribunales por igual parecen frecuentemente perdidos respecto de cómo calcular los daños en un caso en particular. En muchos casos, independientemente de la naturaleza del reclamo, las partes parecen adoptar por defecto metodologias que han sido tradicionalmente aplicadas en casos de expropiación total". (WeIsBurg, Henry, y RYAN, Christopher, Mteans to be made whole: Damages in the context of international investment 
de la inversión o del reclamo una vez surgida la controversia generará, inevitablemente, una importante tensión argumental en la cuantificación de los daños.

Esta tensión surgirá inevitablemente por motivo de que es poco probable que el mercado acepte como precio por el reclamo el valor exagerado reclamado ante los tribunales, y de que los demandantes - 0 sus abogados- temerán seguramente que los tribunales, enterados del valor al que el reclamo ha sido transado, cedan a la tautología de considerar que no hay valor de mercado más certero que el que el mercado determina, reduciendo el monto de los eventuales daños en proporción al precio percibido en la transferencia. En consecuencia, no es poco común -ni por ello menos reprochable- que los demandantes y letrados renieguen de revelar el precio al que transferencias de activos o reclamos se realizan, o lo oculten o sepulten entre miles de páginas de presentaciones numéricas, especialmente cuando esas transferencias ocurren en momentos cercanos a la fechavalor a la que la valuación de daños se realiza."t)

Así, comprobamos que, luego de nacida la controversia, la cesión de la inversión o del reclamo que allí se ha forjado puede tener importantes efectos jurisdiccionales -llegando incluso a privar de jurisdicción a un tribunal de inversión-, pero también que, aun en los casos en que esos efectos no se configuran, la cuestión puede llevar a corolarios de gran interés en la decisión a que el tribunal llegue en materia de méritos, especialmente cuando el precio al que la cesión se realiza difiere notablemente del valor proporcional asignado a la inversión a efectos de la cuantificación de los daños. ${ }^{41}$

arhitration, en Derains, Yves y KREINDLER, Richard (Eds.), Evaluation of Damages in Imternational Arbitration, ICC Publications (2006), pág. 165) (traducción libre). Lucy ReED sostiene, acertadamente, que esa metodologia frecuentemente consiste en la determinación del valor de mercado de la inversión al momento de la expropiación (REeD, op. cit., p. 103).

40. Lamentablemente, motivos de confidencialidad impiden al autor brindar mas detalles sobre algunos casos en que estas experiencias han trasuntado en cálidos debates durante audiencias de mérito ante tribunales del CIADI, pero invitamos cordiaimente al lector a indagar sobre el punto a aquellos colegas que sean vistos sonrojándose al leer estas lineas. 


\section{Cesiones posteriores al dictado del Laudo}

En la sección anterior sosteníamos que la apropiación de premisas jurisdiccionales importadas, como por horror vacui, ${ }^{42}$ de los preceptos rectores de la actividad de la Corte Internacional de Justicia no parece ser el mecanismo más apropiado para explicar y entender la práctica de los tribunales arbitrales del CIADI. De hecho, puede sostenerse que, en el especialísimo marco del Convenio CIADI, las cuestiones y efectos de la nacionalidad de las partes del proceso arbitral no sólo no se agotan al alcanzarse las fechas críticas del artículo 25(2) del Convenio sino que, para diversos propósitos, recién comienzan allí, y se proyectan, incluso, hasta después de dictado el laudo, afectando también la viabilidad $u$ oponibilidad de la cesión que se intente. ${ }^{+3}$

En efecto, si bien la calidad de parte en un arbitraje del CIADI y la jurisdicción ratione personae del Centro a su respecto comienzan, como se discute en la sección anterior, con el perfeccionamiento de los actos requeridos bajo el Convenio por quienes cumplan con los requisitos de nacionalidad en las fechas críticas allí establecidas, esa calidad, y los efectos que se desprenden de ella, constituyen cuestiones de enorme relevancia práctica y jurídica aún después de dictado el laudo, impidiendo que éste sea válidamente transferido a partes distintas de las partes litigantes. Encontramos elementos confirmatorios de estos efec-

41. Sin adentramos en detalle en la materia, resta todavía la cuestión de si, ocurrida la cesiōn del reclamo u otra operación que tenga por efecto desinteresar al inversor originario, puede subsistir la posi. bilidad de realizar un reclamo en arbitraje de inversión. La cuestión es resumida por ScIREUER en los siguientes términos: "Once... the investor may" no longer be am injured pars: [it] may hence have no claim against the host State" (SCIIRFUER, op, cit, comentario al articulo 25 del Convenio CIADI, $\S 305)$.

42. En los albores de la ciencia médica, se consideraba que la naturaleza aborrecia el vacio, y que al realizarse un corte, la sangre fluia desde los órganos hacia los ductos que ahora denominamos 'venas' y 'arterias' importada por fuerza de ese mismo horror al vacio, u 'horror vacui'. A mediados del Siglo XVII, el jurista, fisico y alcalde de Magdeburgo Otto voN GuerICKE (1602-1686), realizó la más recordada demostración del equivoco epistemológice del horror wacti, al generar, con una bomba de su invención, una esfera - paradójicamente- llena de vacio, e inteatar vanamente separarla con 15 pares de caballos.

43. Nuevamente, nos referiremos aqui primordialmente a la cuestión relativa a la cesión de laudos dictados bajo el Convenio CIADI, por entender que reflejan caracteres de esencial interés al estudio del "arbitraje público intemacional" al que se referia Mistzus en la cita con la que comenzamos estas páginas. 
tos en diversas cuestiones, que hemos sistematizado conforme la siguiente clasificación:

\subsection{Efectos Relativos a los Recursos}

Una vez dictado el laudo, surge a su respecto la posibilidad, para las partes, de interponer alguno de los recursos previstos bajo el Convenio CIADI. Estos recursos consisten, según los términos del Convenio, en solicitudes para que el laudo sea rectificado, ${ }^{44}$ aclarado, ${ }^{45}$ revisado ${ }^{46}$ o anulado, ${ }^{47}$ las que, en todos los casos, sólo podrán ser presentadas por las partes litigantes..$^{48}$ Ello lleva, necesariamente, a que no pueda escindirse, en el sistema del Convenio, la calidad de parte en la controversia de la de titular del laudo que se emita, mientras subsista la posibilidad de que cualquiera de las partes interponga a su respecto alguno de los recursos mencionados. ${ }^{49}$

Esta conclusión se hace particularmente insoslayable al analizarse los supuestos fácticos en los que procede, por ejemplo, el recurso de interpretación previsto en el artículo 50 del Convenio CIADI, en cuanto debe existir, para poder solicitarlo, "una diferencia entre las partes acerca del sentido o alcance del laudo".50 Debe

44. Convenio CIADI, $\$ 49(2)$.

45. Id., $\$ 50$,

46. Itl. $\$ 51$.

47. ld., $\$ 52$.

48. Arg. Convenio CIADI. $\$ \S 49(2)$ ("A requerimiento de una de las partes..."), $50(1)$ ("Si surgiere una diferencia entre las partes...cualquiera de cllas podri solicitar"), $51(1)$ ("Cualquiera de las partes podrá pedir...") y 52(1) ("Cualquiera de las partes podrá solicitar...").

49. Respecto de la posibilidad de interpretar que la cesiōn del laudo implicará la sustitución de la calidad de parte litigante a estos efectos, considerames que ello no podria suceder sin que la otra parte o partes en el procedimiento presten su consentimiento al desistimiento de la calidad de parte por cl cedente, por aplicación del claro precepto del articulo 2S(1) del Convenio ("El consentimiento dado por las partes no podrá ser unilateralmente retirado"). La cuestión es aclarada en el lnforme de los Directores Ejecutivos del Banco Mundial que propone la celebración del Convenio CIADI, quienes sostienen que "El presente convenio ofrece métodos internacionales de arreglo destinados a tomar en consideración las caracteristicas especiales de... Ias partes a que habrá de aplicarse. [...] Especificamente, aseguraria que, una vez que un gobierno o un inversionista diera su consentimiento a la conciliación o al arbitraje bajo los auspicios del Centro, tal consentimiento no podria ser revocado unilateralmente" (Informe de los Directores Ejecutivos acerea del Convenio sobre Arreglo de Diferencias Relativas a Inversiones entre Estados y Nacionales de Otros Estados, § II).

50. Convenio CIADI, $\$ 50(1)$. 
notarse, especialmente, que el Convenio CIADI no prevé un plazo dentro del cual pueda solicitarse el recurso de interpretación, como sí sucede con otros recursos allí previstos, ${ }^{51}$ lo cual se condice con la posibilidad de que el laudo ordene prestaciones que no se agoten en un único pago, o que no sean necesariamente un pago en dinero, 52 lo que puede razonablemente suscitar diferencias interpretativas en momentos largamente posteriores al laudo.

La situación es todavía más clara cuando el laudo condena a ambas partes a llevar a cabo prestaciones cruzadas, ya que permitir la cesión de la calidad de parte deudora permitiría una sustracción voluntaria de la jurisdicción del tribunal incompatible con el fin y propósito del Convenio, ${ }^{53}$ que prevé de manera definitoria que "el laudo será obligatorio para las partes", 54 y que "凹las partes lo acatarán y cumplirán en todos sus términos".55

Al respecto, se ha llegado incluso a sostener que la literalidad del laudo -lo que, sin dudas, incluye necesariamente a la designación de las partes allí litigantes- no puede ser modificada ni perder efectividad a menos que se dicte, a su respecto, una decisión de rectificación, aun en caso de que existieran errores en su formulación que pudieran tener efectos sobre el decisorio

51. Estos plazos son de $\mathbf{4 5}$ dias desde la fecha del laudo para la rectificación. pero pueden llegar hasta los tres años para el caso de los procesos de revisión (Convenio CIADI, §51(2)) o anulación (Convenio ClADI, \$52(2)). En todos los casos, en el supuesto de que luego del dictado del laucio se dictara una decisión de rectifícación, esos plazos correrán desde la fecha en que se hubiera dictado esa última decisión (Convenio CIADI, $\$ 49(2)$ ). Debe notarse, finalmente, que respecto de una decisión de anulación puede también interponerse un recurso de rectificación (Convenio CIADI, $\$ 52(4))$, lo que llevará, lógicamente, a que el vencimiento del último de estos plazos se postergue de manera acorde.

52. Nótese, por ejemplo, que Convenio CIADI sólo obliga a los Estados contratantes a hacer ejecutar dentro de su territorio "las obligaciones pecuniarias impuestas por el laudo" (Convenio CIADI, $\$ 54(1)$ ), lo que demuestra que las prestaciones pueden tener un contenido no pecuniario. Al mismo tiempo, encontramos que el Convenio CIADI permite a los Estados prestar protección diplomática a sus nacionales cn caso de que un Estado contratante condenado bajo un laudo CIADI "haya dejado de cumplirlo" (Convenio CIADI, \$27(1)), lo que demuestra que el tribunal puede ordenar prestaciones distribuidas a lo largo de un periodo. El Convenio no contiene disposiciones que regulen la duraciỏn máxima de ese periodo.

53. Arg. Convención de Viena sobre Derecho de los Tratados, \$3।(1).

54. Convenio ClADI, \$53(1) (el subrayado nos pertenece).

55. Ihid. (el subrayado nos pertenece). 
mismo. ${ }^{56}$ Sin pronunciarnos a favor o en contra de esta tesitura, esto implicaría que, en la medida en que ni siquiera el error más burdo o pequeño pueda ser modificado sin intervención del tribunal, no podría derogarse un elemento tan definitorio del laudo como la identidad de las partes por un hecho o acto en el que interviene solamente a una de ellas. A todo evento, resulta necesario coincidir con el corolario expresado por el Prof. SCHREUER de que "todo cumplimiento de buena fe con el texto original del laudo será legítimo hasta tanto el laudo haya sido modificado" ${ }^{57}$

\subsection{Efectos relativos a la Protección Diplomática ${ }^{58}$}

\section{El Convenio CIADI establece que}

Ningún Estado Contratante concederá protección diplomática ni promoverá reclamación internacional respecto de cualquier diferencia que uno de sus nacionales y otro Estado Contratante hayan consentido en someter o hayan sometido a arbitraje conforme a este Convenio salvo que este último Estado Contratante no haya acatado el laudo dictado en tal diferencia o haya dejado de cumplirlo. ${ }^{59}$

Como se ve, las obligaciones derivadas de esta disposición alcanzan sólo a los Estados contratantes del Convenio CIADI, y lo hacen en la medida en que uno de sus nacionales haya sometido una controversia a arbitraje o haya consentido en hacerlo. En la medida en que se permitiera que el laudo circulara a

56. Scurzutr, op, cit. comentario al articulo 53 del Convenio CIADl, \$5] (“...ecten if the omission or the clerical, arithmetical or similar crror concerned affects the performance of the award, the obligation to comply with the awarl in its original form remains unchanged antil the tribimal has given its decision which then becomes part of the awarl".) (el subrayado nos pertenece).

57. Id., $\$ 65$ (traducción libre).

58. Si bien consideramos que la euestión de la protección diplomática demuestra con especial claridad los problemas que afectan la cesibilidad de un laudo CIADI, no dejamos de advertir que, como cuestión epistemológica, cuanto aqui se diga resultará igualmente de aplicación a lo largo de todo cl plazo en que los Estados contratanies bajo el Convenio CIADI se han obligado a no prestar protección diplomática, lo que comienza con el dics a quo con cl consentimiento o sometimiento de la controversia al CIADl (Arg. Convenio CIADI, \$27(1)).

59. Convenio CLADI, $\$ 27$ (1) (cl subrayado nos perenece) 
manos de un nacional de un Estado no contratante, o a alguien distinto de quien consintió en someter la cuestión a arbitraje, esta prohibición no alcanzaría al Estado del cual el nuevo titular fuera nacional, lo que parecería desvirtuar el efecto principal de la disposición.

Comentarios de diversa fuente sobre esta cuestión llevan a la conclusión de que, en la inteligencia del Convenio, el inversor perjudicado en su inversión, la parte litigante y el titular del laudo que dicte un tribunal del CIADI serían una y la misma persona.

Por una parte, se ha sostenido que sólo el Estado del que el inversor perjudicado en su inversión es nacional podría prestar protección diplomática, ${ }^{60}$ lo que lleva a sostener que, dado que un adquirente-cesionario del laudo no habría realizado la inversión a la que se refiere la diferencia, ${ }^{61}$ permitir la cesión del laudo a un nacional de un Estado que no estuviera así impedido de brindar protección diplomática implicaría aceptar un resultado manifiestamente absurdo o irrazonable, ${ }^{62}$ contrario a las reglas de interpretación aplicables al Convenio. ${ }^{.63}$

De otra parte, diversos tribunales arbitrales han sostenido, con marcada elocuencia, que

"el propósito mismo del Convenio CIADI ha sido, justamente, el de proteger a los Estados receptores de intervenciones diplomáticas y 'despolitizar' las relaciones de inversión, por lo que atentaría contra los fines y propósitos del Convenio exponer al Estado al mismo tiempo a presiones diplomáticas y a un reclamo en arbitraje", ${ }^{64}$

60. SCIIREuER, op. cit., comentario al articulo 53 del Convenio CIADI, $\$ 43$ ("Diplomatic protection for the parpose of securing compliance with the avanl may be cxercised by the State of nationality of the aggrieved natural or juridical person"). Ver tambiein, id, $\$ 46$ ("States parties to the ICSID Convention, other than the investor s State of nationalin: have no right of diplomatic protection").

61. Arg. Convenio CIADI, $\$ 25(1)$ ("diferencias de naturaleza juridica que surjan directamente de una inversión").

62. Arg. Convención de Viena sobre Derecho de los Tratados, \$332(b).

63. Ver nota al pic $\# 26$ supra.

64. BANRO c. Congo, Caso ClADI Nro. ARB/98/7, Laudo del 1 de scpticmbre de 2000, $\$ 19$ (traducción libre). 
y que, ya desde una perspectiva histórica, la protección diplomática sólo mantiene su raison d'etre en la medida en que no se produzcan cambios en la nacionalidad del inversor. ${ }^{65}$

Entendemos que el dispositivo contenido en el Convenio CIADI respecto a la protección diplomática explica el punto hasta el que el sistema está diseñado de modo de bloquear la cesión de la calidad de parte en la controversia aun después de que renazca la protección diplomática por aplicación del artículo 27(1), ya que, al impedir esa cesión, "evita una situación en la cual el Estado demandado tiene una obligación para con el Estado reclamante por un perjuicio causado a una persona que ya no es de interés jurídico para ese Estado", "6it lo que coincide con las recomendaciones surgidas de la CDI para la adopción de reglas positivas en materia de protección diplomática. ${ }^{67}$

La situación es todavía más clara cuando la cesión pretendida tiene por cesionario a un nacional del Estado demandado, ya que, en ese caso, por supuesto, no cabría esperar que la protección diplomática fuera permitida en tanto, como comenta con estupor el Informe de la CDI sobre la Protección Diplomática " $i e l$ Estado demandado hubiera tenido entonces que pagar una indemnización a otro Estado respecto de un perjuicio causado a su propio nacional!". 68

65. Loeven c. Estados Unidos, Caso CIADI No. ARB(AF)/98/3, Laudo bajo el Mecanismo Complementario del 26 de junio de 2003, $\$ 229$ ("When investment claims were negotiated and resol"ed only at a governmental level, any change in nationality of the claimant defeated the only reason for the negotiations to comtinte. The claiming government no longer had a citizen to protect").

66. Comisión de Derecho Internacional, Séptimo Informe sobre la Protección Diplomatica (Relator Especial, John Dugard) (2006), Documento A/CN.4/567, $\$ 38$.

67. Ihid. ("[d]esde el punlo de vista sustantivo, esta norma es preferible").

68. Id., $\$ 40$. 


\subsection{Efectos Relativos al Reconocimiento y ejecución del laudo}

Para finalizar, anotaremos también que el sistema de arbitraje contenido en el Convenio CIADI también restringe la posibilidad de instar el reconocimiento y ejecución de un laudo exclusivamente a las partes litigantes al establecer, en el artículo 54 , los pasos que deberá seguir "II]a parte que inste el reconocimiento o ejecución del laudo en los territorios de un Estado Contratante" ${ }^{69}$

Comentando esta disposición, el Prof. SCHREuer sostiene, de manera categórica, que "el artículo 54 no distingue entre el reconocimiento y ejecución contra inversores, por una parte, y contra Estados receptores por la otra. En consecuencia, esto puede ser realizado por cualquiera de las partes del procedimiento arbitral" ${ }^{70}$

Lejos de constituir una coincidencia terminológica, se ha sostenido con convicción que el dispositivo del artículo 54 debe leerse conjuntamente con los requisitos de nacionalidad del artículo 25 -de donde se sigue que estos deben mantenerse hasta el momento de la eventual ejecución del laudo-, ya que ello constituye el sinalagma acordado entre los Estados contratantes bajo el Convenio para establecer condiciones de reciprocidad en materia de obligaciones relativas al reconocimiento y ejecución de laudos CIADI. ${ }^{71}$ En consecuencia, veremos que si se permitiera que el reclamo o el laudo circularan entre el sometimiento de una controversia a la jurisdicción del Centro y la ejecución del laudo que se dictara en su consecuencia, se violaría el compromiso negociado y alcanzado entre los Estados contratantes respecto de sus obligaciones recíprocas.

69. Convenio CIADI, $\$ 54(2)$.

70. SCHREUT:k, op. cit., comentario al articulo 54 del Convenio CIADI, $\$ 7$ (traducción libre) (cl subrayado nos pertenece).

71. Id. $\$ 26$ ("The requinement under Art. 25 that the investor must be a national of a Contracting State assures that its State of nationality will be hotund by Art. 54") (citas internas omitidas). 


\section{CONCLUSIÓN}

La historia moderna de la humanidad muestra que, de tiempo en tiempo, y a pesar de los notables avances en las ciencias, las artes y en la conciencia generalizada respecto de ciertos derechos inalienables, no ha podido todavía erradicarse la posibilidad de que un Estado adopte conductas que resultan violatorias de sus obligaciones internacionales, causando daños a nacionales o extranjeros por los que resulta responsable bajo el derecho internacional. Esto incluye, como mencionábamos al comenzar estas líneas, el campo cada vez más fértil del derecho internacional de las inversiones, cuyos postulados en materia obligacional y compensatoria no se alejan, con todo, del tronco común del derecho internacional general.

En consecuencia, así como seguramente encontraremos fuerte reticencia a aceptar que una entidad financiera que adquiera a valor vil los derechos a compensación de víctimas de 'limpiezas étnicas' tenga el mismo ius standi que las víctimas mismas para reclamarlas a su pleno valor, debemos cuidarnos también muy bien de permitir que terceros que no realizaron inversión alguna en el territorio de un Estado invoquen desembozadamente derechos ajenos como reclamos propios, sobre todo en la medida en que, como consecuencia de esos reclamos, no resulta beneficiado el inversor perjudicado, ni el Estado receptor, ni el sistema internacional de las inversiones, $\mathrm{ni}$ el desarrollo económico ni humano de una población o un conjunto de ellas, sino sólo quien, especulando con los derechos ajenos, se entromete en una relación jurídica sin otro propósito que acuñarse en las hendiduras del sistema de derecho internacional para su propio beneficio económico.72

72. En algunas jurisdicciones del common law, subsisten todavia vestigios del antiguo derecho feudal, que, bajo la denominación de mantenance y de champerñ: apuntan, con efectos reducidos respecto de los originales, a impedir y penalizar la interferencia en los reclamos ajenos (maintenance). lo que se considera agravado en caso de que esa interferencia tuviera por objeto cl hacerse con una porción del producido de ese reclamo (champerty). Sin adentramos en esta instancia en el efecto particular de ciertos arreglos de honorarios contingentes o de financiamiento de litigios sobre las cuestiones que aqui debatimos, encontramos recomendable recordar que instituciones de este tipo, o las que, por 
A lo largo de estas páginas nos hemos pronunciado acerca de los límites dentro de los cuales un inversor puede legítimamente transferir sus derechos sobre un determinado proyecto sin sacrificar por ello el acceso a los mecanismos de tutela supranacional que la gran mayoría de los Estados han diseñado -luego de sesudas negociaciones bilaterales y multilaterales- en su beneficio exclusivo. Es nuestra esperanza que estas líneas sirvan como combustible para el debate acerca de los elementos que deben tenerse en cuenta para que la circulación de esos activos suceda sin pérdida para el inversor, y sin violar los acuerdos así alcanzados, ni sus fines y propósitos.

Buenos Aires, Agosto de 2010.

razón del tiempo, las han sucedido en el desarrollo del derecho moderno, deben todavia ser honradas en el panteón de las normas venerables. Para una interesante discusión de estas instituciones en la práctica modema del arbitraje internacional, ver NG, Jem-Fei, United Kingdom: The Role of the Doctrines of Champerty and Maintenance in Arbitration, disponible en http: $/ /$ www,mondaq. com/article asp? article_id $=303272$ 